are not available, because the time within range for these patients was drawn from historical data obtained from our anticoagulation clinic. Finally, although linear interpolation is a well validated and accurate method for estimating time within the therapeutic INR range, it is still possible that not all fluctuations in the INR were detected by this analysis.

In conclusion, the results of our pilot study suggest that HeartMate II recipients may spend a significant amount of time with values outside the target INR range. We saw this deviation despite relatively normal warfarin dosage requirements. Additional studies exploring the etiology of this potentially altered pharmacodynamic response are warranted. Practitioners implanting left ventricular assist devices should closely monitor the INR of these patients to ensure optimal levels of anticoagulation.

\section{References}

1. Uriel N, Pak SW, Jorde UP, Jude B, Susen S, Vincentelli A, et al. Acquired von Willebrand syndrome after continuous-flow mechanical device support contributes to a high prevalence of bleeding during long-term support and at the time of transplantation. J Am Coll Cardiol. 2010;56:1207-13.

2. Rosendaal FR, Cannegieter SC, van der Meer FJ, Briët E. A method to determine the optimal intensity of oral anticoagulant therapy. Thromb Haemost. 1993;69:236-9.

3. John R, Kamdar F, Liao K, Colvin-Adams M, Miller L, Joyce L, et al. Low thromboembolic risk for patients with the Heartmate II left ventricular assist device. J Thorac Cardiovasc Surg. 2008;136:1318-23.

4. Boyle AJ, Russell SD, Teuteberg JJ, Slaughter MS, Moazami N, Pagani FD, et al. Low thromboembolism and pump thrombosis with the HeartMate II left ventricular assist device: analysis of outpatient anti-coagulation. J Heart Lung Transplant. 2009;28:881-7.

\title{
An unusual case of chyloptysis
}

Rebecca Tregunna, MBBS, BSc, ${ }^{\mathrm{a}}$ Elizabeth Belcher, MRCP, FRCS, PhD, ${ }^{\mathrm{a}}$ Paul Cane, FRCPath, ${ }^{\mathrm{b}}$ and Loic Lang-Lazdunski, MD, PhD, ${ }^{\mathrm{a}}$ London, England

Chyloptysis is rare and usually occurs spontaneously secondary to disorders of the mediastinal lymphatic system. We present a case of chyloptysis after cervical mediastinoscopy and biopsy of mediastinal lymphadenopathy.

\section{CLINICAL SUMMARY}

A 59-year-old man presented with a 3-month history of a cough producing white sputum streaked with occasional minor hemoptysis. His medical history was unremarkable other than a pericardial effusion, not noted to be chylous in nature and of unknown cause, requiring percutaneous drainage without complication 10 years previously. $\mathrm{He}$ was a nonsmoker. Examination results were unremarkable with no evidence of yellow nail syndrome. Computed tomography (CT) of the chest demonstrated widespread paratracheal lymphadenopathy, anterior mediastinal mass, and normal lung fields (Figure 1, $A$ ). Subsequent bronchoscopy results were normal. Cervical mediastinoscopy confirmed extensive mediastinal lymphadenopathy. Chyle was noted to reflux on manipulation of tissues; however, no evidence

From the Departments of Thoracic Surgery ${ }^{\mathrm{a}}$ and Histopathology, ${ }^{\mathrm{b}}$ Guy's Hospital, Great Maze Pond, London, England.

Disclosures: Authors have nothing to disclose with regard to commercial support. Received for publication Oct 22, 2010; accepted for publication March 21, 2011.

Address for reprints: Loic Lang-Lazdunski, MD, PhD, Department of Thoracic Surgery, Guy's and St Thomas' NHS Trust, Great Maze Pond, London, SE1 7RT (E-mail: loic.lang-lazdunski@gstt.nhs.uk).

J Thorac Cardiovasc Surg 2011;142:e2-3

$0022-5223 / \$ 36.00$

Copyright (c) 2011 by The American Association for Thoracic Surgery doi:10.1016/j.jtcvs.2011.03.012 of elevated lymphatic pressure or hemorrhage was noted. Biopsy of mediastinal nodes (stations 2 and 4) was without complication and showed only reactive changes, with no evidence of granuloma formation or malignancy after histopathologic examination.

After this procedure, the patient presented again with a worsening cough and shortness of breath. He now described his sputum as being of "fried egg" appearance. Analysis of sputum confirmed chyloptysis (triglyceride, $14.7 \mathrm{mmol} / \mathrm{L}$; cholesterol, $2.0 \mathrm{mmol} / \mathrm{L}$ [ratio 7.4:1]). Repeat CT of the chest showed a $90-\mathrm{mm}$ anterior mediastinal mass with patchy parenchymal opacification in the lingula and left lower lobe, but no evidence of pleural effusion (Figure 1, $B$ ). Lymphangiography was not undertaken. The patient underwent median sternotomy and resection of this anterior mediastinal mass. At operation, chyle was noted draining from the cut tumor surface. Multiple small vessels were noted between the mass and hilum of the left lung, which were divided using the Harmonic scalpel; however, the mass did not invade into the lung parenchyma, and pulmonary resection was not deemed necessary. BioGlue (CryoLife, Europa Ltd, Surrey, UK) was applied over the resection area in an attempt to reduce the risk of chylothorax in the early postoperative period.

Histopathologic examination showed predominantly adipose tissue interspersed with cystically dilated spaces containing grey, chylous fluid and multiple congested blood vessels with focal punctate hemorrhage confirming a typical lymphangioma (Figure 2). The patient made a satisfactory postoperative recovery with no further chyloptysis at 7 months postoperatively. 


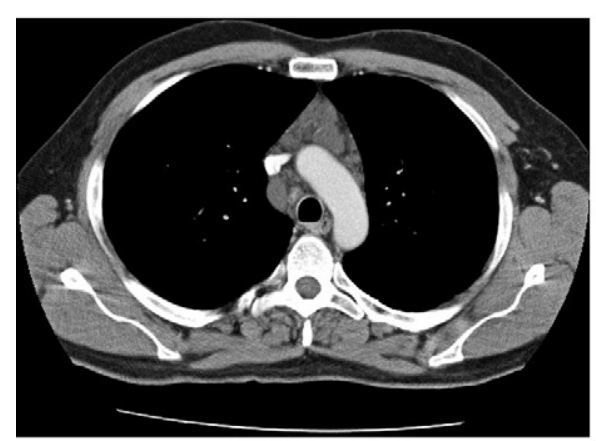

A

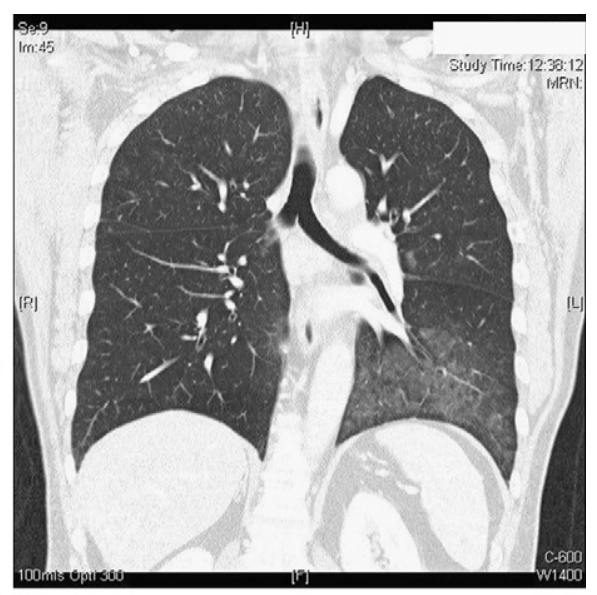

B

FIGURE 1. A, Contrast CT scan of the chest showing anterior mediastinal mass and paratracheal lymphadenopathy at first presentation. B, Reconstructed CT scan of the chest showing opacification of the left lower lobe secondary to chyle within the bronchoalveolar tree.

\section{DISCUSSION}

The differential diagnosis of primary chyloptysis includes lymphangioma, lymphangiomatosis, lymphangiectasis, lymphatic dysplasia syndrome, and lymphangiomyomatosis. Lymphangiomas are the most common of all mediastinal lymphatic disorders comprising up to $4.5 \%$ of all mediastinal tumors. ${ }^{1}$ They are benign tumors characterized by dilated lymph-filled cystic sacs ${ }^{1}$ that are abnormally formed during fetal development by failure of the primary lymphatic cavities to join with the central lymphatic system ${ }^{2}$ and usually present in infancy. ${ }^{3}$ Acquired lymphangiomas may occur secondary to chronic infection, surgery, or radiation because of chronic obstruction of the lymphatic system. ${ }^{3}$

Mediastinal lymphangiomas may be an incidental finding, however. In one study of 25 cases, $75 \%$ were symptomatic secondary to compression of adjacent structures presenting with dyspnea, chest pain, or hemoptysis. ${ }^{1}$ In the present

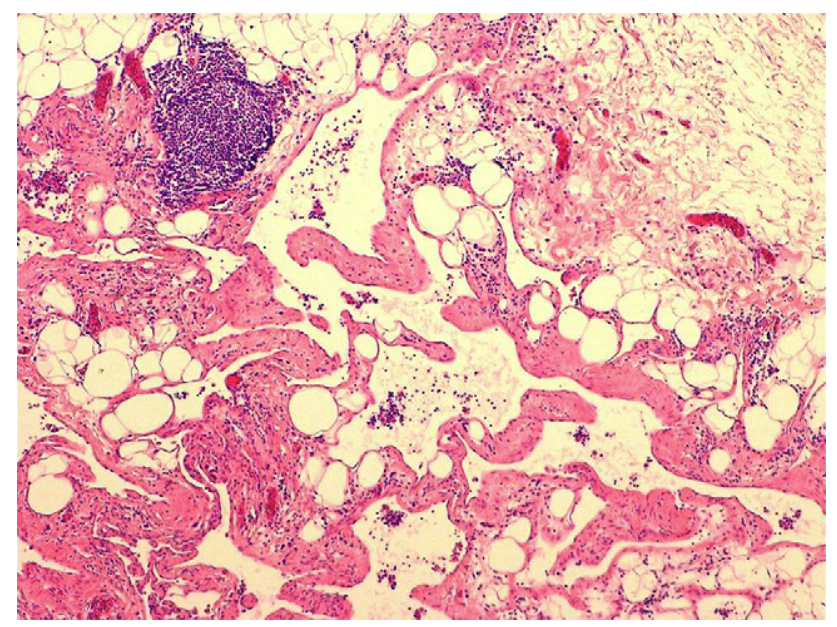

FIGURE 2. Microscopic appearance of lymphangioma showing dilated lymphatic channels filled with lymph. Hematoxylin-eosin staining $(100 \times$ magnification). case, the patient initially presented with cough, and chyloptysis developed only after cervical mediastinoscopy; therefore, it seems to have been induced iatrogenically. Surgical trauma associated with cervical mediastinoscopy, leading to the development of acquired lymphangioma, may have resulted in elevation of lymphatic pressure and retrograde flow of chyle through the lymphatic within the bronchial tree. ${ }^{3}$ This retrograde flow is the other postulated mechanism for the development of chyloptysis. ${ }^{4}$ Alternatively, biopsy of the paratracheal lymph nodes may have resulted in the development of a chylous effusion in association with a bronchopleural fistula and thus chyloptysis, this being one of the proposed mechanisms for its development. ${ }^{5}$

\section{CONCLUSIONS}

Surgical excision of lymphangioma resulted in complete resolution of chyloptysis. Complete surgical resection is the treatment of choice, as was performed in the present case, although radiation, chemotherapy, laser, and sclerosing agents have been described with varying success. ${ }^{1}$ To our knowledge, this is the first reported case of iatrogenicinduced chyloptysis.

\section{References}

1. Park JG, Aubry M-C, Godfrey JA, Midthun DE. Mediastinal lymphangioma: Mayo Clinic experience of 25 cases. Mayo Clin Proc. 2006;81:1197-203.

2. Godart S. Embryological significance of lymphangioma. Arch Dis Child. 1966; 41:204.

3. Faul JL, Berry GJ, Colby TV, Ruoss SJ, Walter MB, Rosen G, et al. Thoracic lymphangiomas, lymphangiectasis, lymphangiomatosis, and lymphatic dysplasia syndrome. Am J Respir Crit Care Med. 2000;161:1037-46.

4. Lim KG, Rosenow EC 3rd, Staats B, Couture C, Morgenthaler TI. Chyloptysis in adults: presentation, recognition, and differential diagnosis. Chest. 2004;125: 336-40.

5. Kinmonth JB. Chylous diseases and syndromes, including references to tropical elephantiasis. In: Kinmonth JB, ed. The lymphatics: surgery, lymphography and diseases of the chyle and lymph systems. 2nd ed. Baltimore, Md: Edward Arnold; 1982:221-68. 